\title{
Um balanço do SUS, próximo da maioridade
} Weighing up SUS as it comes of age

\author{
Paulo Henrique Rodrigues \\ Professor do Mestrado Profissional em \\ Saúde da Família - Universidade Estácio de Sá \\ pharodrigues@gmail.com
}

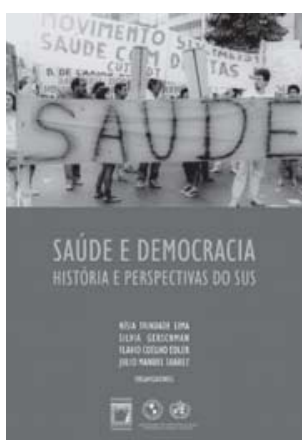

Lima, Nísia Trindade de; Gerschman, Sílvia; Edler, Flávio Coelho; Suárez, Julio Manuel (Org.).

Saúde e democracia: histórias e

perspectivas do SUS. Rio de Janeiro: Ed. Fiocruz, 2006. 502p.
$\mathrm{O}$ livro Saúde e democracia: histórias e perspectivas do SUS traz 15 artigos que abordam temas da história e dos principais desafios do Sistema que acaba de completar 18 anos, a contar da promulgação da Constituição de 1988 .

No artigo "A saúde na construção do Estado nacional no Brasil: reforma sanitária em perspectiva histórica", Nísia Trindade Lima, Cristina M.O. Fonseca e Gilberto Hochman fazem balanço da herança histórica do movimento sanitarista, questionando duas tendências: (1) a que busca tratar o presente de forma inaugural, sem continuidade com o passado; e (2) aquela que, ao contrário, sublinha uma continuidade um tanto fatalista de duas marcas do destino brasileiro, as desigualdades e a exclusão social. $\mathrm{O}$ texto resgata as experiências de reforma no século XX. O fio condutor é a relação entre saúde e desenvolvimento, que deu origem ao chamado sanitarismo campanhista, simbolizado pelos antigos Departamento Nacional de Saúde Pública (DNSP) e Departamento Nacional de Endemias Rurais (DNERu). O questionamento desse modelo era feito pelos 'sanitaristas desenvolvimentistas', que propunham a integração de prevenção e assistência e lideraram a $3^{a}$ Conferência Nacional de Saúde, propondo a redefinição das responsabilidades entre os entes federados e a municipalização das ações de saúde, rumos abortados pelo golpe militar de 1964.

Sarah Escorel, Dilene Raimundo do Nascimento e Flavio Coelho Edler, em "As origens da reforma sanitária e do SUS", localizam a origem do movimento sanitário nos Departamentos de Medicina Preventiva, surgidos a partir de 1968, que buscaram transferir o foco da atenção individual para as questões sociais e coletivas. Mostram como suas lideranças conseguiram ocupar cargos na burocracia pública e passaram a influenciar a política de saúde. Destacam o papel de instituições como o Instituto de Medicina Social da Uerj, a Fundação Oswaldo Cruz (Fiocruz), o Centro Brasileiro de Estudos de Saúde (Cebes) e a Associação Brasileira e Pós-graduação em Saúde Coletiva (Abrasco) na reforma sanitária. O texto parece reforçar uma versão cada vez mais presente na interpretação do movimento e da reforma sanitária, segundo a qual os protagonistas seriam principalmente da academia, de onde teriam partido para ocupar espaços públicos. Contudo nessa interpretação não parece haver lugar para protagonistas da base da sociedade, como os Movimentos de Saúde Comunitária e Popular pela Saúde, nem para o antigo Partido Comunista Brasileiro. 
O papel das Conferências Nacionais de Saúde é tratado por Sarah Escorel e Renata Arruda de Bloch no artigo "As Conferências Nacionais de Saúde na construção do SUS". Nele, as autoras destacam o papel da $3^{\text {a }}$ Conferência Nacional de Saúde (CNS) no governo Goulart e, entre as conferências realizadas sob o regime militar, chamam a atenção para os debates da 5 $5^{a}$ CNS (1975) - participação da população - e da $7^{\mathrm{a}}$ CNS (1980) - Programa Nacional e Serviços Básicos de Saúde (Prev-Saúde). Apontam ainda o papel, a importância e a legitimidade da $8^{a}$ CNS. Sublinham também as dificuldades para a realização da $9^{a}$ CNS, no governo Collor; o peso dos municípios nessa conferência; e o surgimento de um "verdadeiro fosso cultural entre tecnocratas ... e a grande massa dos delegados eleitos", apontado por Madel Luz (citado em Escorel, Bloch, 2005, p.103). Tal fosso indicaria um possível e preocupante afastamento entre o movimento sanitário e o movimento popular que deu sustentação social à reforma sanitária e ao Sistema Único de Saúde (SUS).

Gastão Wagner de Sousa Campos assina "Romance de formação de um sanitarista: um estudo de caso", em que aborda a trajetória dos integrantes do movimento sanitário utilizando sua história pessoal como fio condutor da narrativa, inspirado no gênero de literatura conhecido por 'romance de formação'. Relata sua trajetória pessoal para ilustrar a formação dos sanitaristas brasileiros envolvidos na crítica e na transformação do sistema de saúde. Destaca que o forte pathos idealista que animou os integrantes do movimento sanitário até o período Collor poderia estar em declínio. Estaria ocorrendo, em sua opinião, uma crescente perda do sentido de militância, desde que as idéias neoliberais ganharam força no mundo e no Brasil, e a maioria dos sanitaristas passou a se dividir entre a burocracia do SUS e a universidade, alguns tendo passado a ambicionar diretamente o poder.

José Carvalho de Noronha, Telma Ruth Pereira e Francisco Viacana discutem as condições de saúde da população brasileira em "As condições de saúde dos brasileiros: duas décadas de mudanças (1980-2000)". Mostram a queda da mortalidade geral, infantil e em menores de cinco anos, além do aumento da esperança de vida. Apesar da melhora, os números relativos a esses indicadores ainda colocam o Brasil numa situação inferior à dos países mais desenvolvidos. Segundo os autores, a acentuada queda da importância das doenças infecciosas e parasitárias não fez com que o controle de algumas doenças desse grupo deixasse de ser motivo de preocupação. Chamam a atenção, ainda, para os desafios propostos pelo rápido envelhecimento da população, que se faz acompanhar pelo aumento das condições crônicas de saúde.

As dificuldades do financiamento do SUS são tratadas por Maria Alicia D. Ugá e Rosa Maria Marques, no artigo "O financiamento do SUS: trajetória, contexto e constrangimentos". Mostram que, apesar da implantação do SUS, o gasto em saúde no Brasil continua sendo majoritariamente privado, ao contrário do que ocorre em outros países que contam com sistemas universais de saúde. O texto aponta também como o SUS, embora tenha resistido às pressões neoliberais pela redução da oferta de serviços públicos de saúde, acabou sofrendo os efeitos do ajuste macroeconômico, que limitaram os recursos disponíveis 
para o seu financiamento. $\mathrm{O}$ enfraquecimento da seguridade social levou ao fim dos repasses da Previdência para o SUS e deu início a uma forte instabilidade das fontes de recursos deste último. Apesar dessas dificuldades, as autoras chamam a atenção para o aumento progressivo do volume de recursos federais para a saúde. Paradoxalmente, a crescente descentralização do Sistema contribuiu para a redução relativa da União como principal financiador - de 77,7\% do total, nos anos 80, para 58,3\% em 2000 (p.216).

Reinaldo Guimarães, em "Ciência, tecnologia e inovação: um paradoxo na reforma Sanitária", trata das relações entre o SUS e as atividades de ciência, tecnologia e inovação (C\&T\&I) na área da saúde, destacando que o esforço de pesquisa na área responde por " $25 \%$ de toda a pesquisa realizada no país" (p.235). Lança mão do exemplo dos filhos de Carlos Chagas, Evandro Chagas e Carlos Chagas Filho, para ilustrar dois padrões de desenvolvimento da pesquisa em saúde no Brasil. Evandro desenvolveu, como o pai, uma carreira voltada para a pesquisa das endemias rurais, enquanto Carlos seguiu direção oposta, dedicando-se aos mecanismos do fenômeno biológico, em maior sintonia com os rumos da pesquisa em saúde internacional. Segundo Guimarães, os dois padrões indicariam uma fratura no modo de se encarar a pesquisa em saúde no Brasil: o debate entre o papel da pesquisa básica ('internacional') e a pesquisa aplicada ('nacional'). O artigo defende também um conjunto de mudanças na política de C\&T\&I em saúde.

Em "Trabalhadores da saúde e sua trajetória na reforma sanitária", Maria Helena Machado avalia o desenvolvimento da situação e das políticas de recursos humanos nas últimas duas décadas. Mostra o enorme salto ocorrido no número de empregos no setor de saúde, que passou de 573 mil, em 1980, para mais de 2,2 milhões em 2002. O SUS teve papel decisivo nesse aumento, pois o número de empregos no setor público cresceu 4,5 vezes no período - passando de 266 mil para 1,19 milhão -, enquanto o do setor privado aumentou apenas 3,2 vezes (p.269). Assinala ter sido nos municípios onde ocorreu a maior parte desse aumento de empregos no setor. Outras características do crescimento do emprego no setor de saúde brasileiro são: sua 'feminilização' (70\% dos empregados são mulheres); elevada terceirização dos recursos humanos; e ausência de uma política de valorização dos recursos humanos no SUS, uma verdadeira 'antipolítica de $\mathrm{RH}^{\prime}$. O texto defende a mudança de atitude nessa área, apostando nos resultados da $3^{\text {a }}$ Conferência de Gestão do Trabalho e da Educação em Saúde (2006).

Marta Arretche analisa criticamente o processo de construção institucional do SUS, no artigo "A política da política de saúde no Brasil". Destaca duas características centrais e paradoxais que conformam o Sistema: a continuidade do setor privado, ao lado de um sistema público universalista; e a enorme concentração de poder no Ministério da Saúde, a despeito da perspectiva de descentralização do setor. $\mathrm{O}$ conflito federativo aberto pela redemocratização teria motivado manobras do Ministério da Saúde visando superar os limites à sua autoridade. Nesse movimento, o Ministério teria se transformado, ao mesmo tempo, na principal arena decisória na formulação da política nacional e "no ator mais poderoso no processo de implementação da reforma" 
(p.286). Essa 'descentralização concentradora' teria se iniciado no governo Collor, quando a Lei 8.080/90 esvaziou o papel dos estados, ao entregar aos municípios a gestão das ações e serviços e assegurar à União o comando do Sistema. O processo teria sido concluído no governo de Fernando Henrique Cardoso, com a NOB 96, que permitiu ao Ministério fortalecer o controle sobre estados e municípios, os quais têm de aderir às suas regras para ter acesso a recursos financeiros.

O processo de descentralização da saúde no Brasil é analisado por Silvia Gerschman e Ana Luiza D'Ávila Viana em “Descentralização e desigualdades regionais em tempos de hegemonia liberal". As autoras defendem que a proposta de descentralização do SUS, nascida da vontade do movimento sanitário de promover uma democratização efetiva da política de saúde, teria se transformado num processo ingovernável de municipalização, em que a cooperação não é necessariamente a tônica. Com base na evolução tanto dos procedimentos ambulatoriais e hospitalares, quando das transferências de recursos financeiros federais para estados e municípios, as autoras concluem que a descentralização estaria operando de forma a favorecer os municípios em que vivem as faixas extremas da população, ou seja, os muito pequenos (com menos de cinco mil habitantes), devido aos recursos para a atenção básica, e os muito grandes (com mais de 500 mil habitantes), em razão das transferências para remuneração de serviços. Portanto, a descentralização não estaria contribuindo para alterar o padrão ainda muito diferenciado da oferta de serviços de saúde entre as diferentes regiões do país.

A participação da sociedade no SUS através dos conselhos de saúde é o tema de Maria Eliana Labra em "Conselhos de Saúde: dilemas, avanços e desafios". Sua tese é que os conselhos enfrentam enormes dificuldades no nível local e vêem questionadas sua legitimidade e eficácia. Entre as razões que contribuiriam para o enfraquecimento do papel dos conselhos de saúde, Labra destaca: falta de representatividade dos conselheiros; precárias condições operacionais e de infra-estrutura; pequeno conhecimento da população a seu respeito; e invasão do seu espaço pelas comissões intergestores. Segundo a autora, cerca de 70\% dos representantes dos usuários nos conselhos provêm de associações de moradores, as quais contariam com baixa participação da população em suas atividades e viveriam fortes conflitos internos.

"O SUS e o direito à saúde: universalização e focalização nas políticas de saúde", de Amélia Cohn, levanta a possível existência de um choque entre universalismo e focalização no SUS. Aborda a questão da focalização de forma parecida com o que Bobbio (1992) chama de 'tendência à especificação crescente dos direitos sociais', em que se volta cada vez mais para necessidades próprias de setores da sociedade como mulheres, crianças, idosos e portadores de deficiência. A especificação não conflita com a universalização; já a focalização significa o direcionamento exclusivo das políticas para determinados grupos mino-ritários, considerados mais vulneráveis, ou 'vítimas' do sistema. A focalização foi bandeira levantada pelo Banco Mundial nos anos 90 e corresponde ao modelo liberal de política social, em que o Estado dirige suas ações apenas para os grupos mais vulneráveis. Trata-se do 
oposto do pretendido não só pela reforma sanitária brasileira, mas também pela Constituição de 1988. O artigo pode servir de alerta para a proliferação, no Brasil recente, de políticas focalizadas como o Bolsa Família, ou a introdução de cotas raciais nas políticas de educação e saúde, inspiradas na experiência dos Estados Unidos.

No artigo "O SUS e os desafios da universalização do direito à saúde: tensões e padrões de convivência entre o público e o privado no sistema de saúde brasileiro", Ligia Bahia discute a tensa convivência entre os interesses públicos e privados na saúde brasileira, defendendo que a reforma sanitária não afastou de lugares estratégicos os interesses privados, os quais teriam refeito seus vínculos com o Estado. Chama a atenção para a grande lacuna de conhecimento sobre as relações entre o SUS e o setor privado de saúde. Até onde essa convivência é prejudicial à universalização do direito e do acesso aos serviços de saúde é questão complexa e ainda não respondida. Resta saber se a complexidade do problema se explica como quer a autora, por uma suposta "desconstitucionalização dos direitos sociais" (p.434), ou pelo afastamento do SUS das "concepções de universalização do bem-estar e das bases de financiamento da seguridade social" (p.434).

Os desafios e as perspectivas do modelo de atenção do SUS são tratados por Carmen Fontes Teixeira e Jorge Pereira Solla, em "Modelo de atenção à saúde no SUS: trajetória do debate conceitual, situação atual, desafios e perspectivas". Os autores fazem um balanço da trajetória da reforma sanitária brasileira visando a mudança do modelo assistencial individualizado e centrado nos hospitais. Destacam o papel do Programa Saúde da Família e defendem a necessidade de mudança do modelo de atenção na rede hospitalar, área em que não teria havido quase nenhum progresso, permanecendo ela concentrada nos grandes centros urbanos do Sul e Sudeste do país, sem perfil assistencial definido e em desacordo com as necessidades da população, além de desintegrada da rede.

Luiza Sterman Heimann e Maria Helena Mendonça assinam o artigo final, "A trajetória da atenção básica em saúde e do Programa de Saúde da Família no SUS: uma busca de identidade". As autoras fazem um balanço do Programa Saúde da Família. Defendem que a definição de atenção básica, adotada como um dos pressupostos do Programa, é superior à concepção de atenção primária à saúde, preconizada pela Organização Mundial da Saúde e pela Organização Pan-Americana da Saúde desde a histórica Conferência de Alma-Ata (1978). Heimann e Mendonça afirmam que a concepção brasileira superaria uma 'proposição preventivista' que estaria presente na concepção de atenção primária à saúde, argumento que parece requerer maior fundamentação.

\section{REFERÊNCIAS BIBLIOGRÁFICAS}

Bobbio, Norberto 1992

Escorel, Sarah; Bloch, Renata Arruda de 2005
A era dos direitos. Rio de Janeiro: Campus.

As Conferências Nacionais de Saúde na construção do SUS. In: Lima, Nísia Trindade et al. (Org.). Saúde e democracia: história e perspectivas do SUS. Rio de Janeiro: Ed. Fiocruz. p. 83-119. 